Vol 3. No 2. Agustus 2019

ISSN 2580-5029

\title{
Indeks Kualitas Perairan dan Fitoplankton Periode Ramadan di Situ Gintung, Tangerang Selatan, Banten
}

\author{
Yayan Mardiansyah Assuyuti1,2*, Alfan Farhan Rijaluddin'1, Firdaus Ramadhan ${ }^{1}$ \\ 1Program Studi Biologi, Fakultas Sains dan Teknologi, UIN Syarif Hidayatullah, Jl. Ir. H. Juanda No. \\ 95 Ciputat, Tangerang Selatan, Banten, Indonesia 15412 \\ ${ }^{2}$ Laboratorium Ekologi, Pusat Laboratorium Terpadu, UIN Syarif Hidayatullah, Jl. Ir. H. Juanda No. \\ 95 Ciputat, Tangerang Selatan, Banten, Indonesia 15412 \\ *ymar.assuyuti@uinjkt.ac.id
}

\begin{abstract}
The behavior of the Indonesian Muslim community has changed in the month of Ramadan and will affect the anthropogenic wast that enters the lake ecosystem. The study was conducted in Situ Gintung Lake, South Tangerang City, in the period before (BR), time (DR) and after (AR) Ramadan 2015. The aims of study was to determine (i) the chemical, physical and water quality using the water quality index (WQI), (ii) phytoplankton classification using codons, pollution and Saprobit indices and (iii) the correlation of chemical and physical of waters with phytoplankton. Water temperature, transparency, TDS and conductivity have significant differences (ANOVA, $p<0.05$ ) in all periods except $\mathrm{pH}$, DO and NPP $(p>0.05)$ with WQI was a medium to good categories. Classification of phytoplankton codons, algae and Saprobit pollution indices values showed that Situ Gintung had meso to eutrophic categories and showed contamination in all periods, respectively. Canonical Correspondence Analysis (CCA) shows that phytoplankton correlate with $\mathrm{BOD}_{5}$.
\end{abstract}

Keywords: CCA, Phytoplankton, Ramadan, Situ Gintung, WQI

\section{ABSTRAK}

Perilaku masyarakat muslim Indonesia telah berubah di bulan Ramadan, sehingga diduga mempengaruhi jumlah antropogenik yang masuk ke ekosistem danau. Penelitian ini dilakukan di danau Situ Gintung, Kota Tangerang Selatan, di periode sebelum (BR), saat (DR) dan setelah (AR) Ramadan 2015. Tujuan dari penelitian adalah untuk mengetahui (i) paramater kimia, fisik dan kualitas perairan menggunakan indeks kualitas perairan (WQI), (ii) klasifikasi fitoplankton menggunakan kodon, polusi indeks dan indeks Saprobit dan (iii) hubungan parameter kimia dan fisik perairan dengan fitoplankton. Suhu air, kecerahan, TDS dan konduktifitas memiliki perbedaan yang nyata (ANOVA, $p<0.05)$ di semua periode kecuali $\mathrm{pH}$, DO dan NPP $(p>0.05)$ dengan kualitas perairan berdasarkan WQI memiliki kategori sedang sampai dengan baik. Berdasarkan klasifikasi fitoplankton menunjukkan Situ Gintung memiliki kategori meso sampai eutrofik dan nilai indeks polusi alga dan Saprobit menunjukkan tercemar di semua periode. Hasil dari Canonical Correspondence Analysis (CCA) menunjukkan bahwa fitoplankton berkorelasi dengan $\mathrm{BOD}_{5}$.

Kata Kunci: fitoplankton, CCA, Ramadan, Situ Gintung, WQI 


\section{PENDAHULUAN}

Ekosistem danau mengalami tekanan dalam beberapa dekade terakhir karena pertambahan jumlah dan aktivitas masyarakat. Menurut Duan et al. (2009) hal tersebut menyebabkan kualitas ekosistem danau menurun. Kualitas perairan ekosistem danau di perkotaan mengalami dampak dari limbah antropogenik dan pabrik sehingga mempengaruhi langsung atau tidak langsung terhadap flora dan fauna. Limbah tersebut menyebabkan penurunan kualitas perairan (Chen et al. 2016), blooming algae (Duan et al. 2009; Deng et al. 2014), menggangu kesehatan masyarakat (Zhang et al. 2009), eutrofikasi, kontaminasi limbah terhadap flora dan fauna dan invasif spesies (Brönmark \& Hansson, 2002).

Aktivitas sosial dan masyarakat muslim di Indonesia, Malaysia (Ra, 2016) dan Mesir (Afifi, 1997) telah berubah di periode bulan sebelum, saat dan setelah Ramadan. Perubahan aktifitas masyarakat pada bulan Ramadan menyebabkan volume sampah meningkat (Muhtarom, 2010; Wardiha dkk, 2014; Yildirim et al. 2016) sehingga secara langsung atau tidak langsung mempengaruhi jumlah limbah di danau. Limbah yang masuk ke danau menyebabkan penurunan kualitas perairan (Chen et al. 2016), mempengaruhi jumlah nutrien, racun sianobakteri, komunitas mikroba (Wilhelm et al. 2011), polutan dan makroinvertebrata (Cai et al. 2011).
Situ Gintung adalah salah satu danau yang terlatak di kota Tangerang Selatan dengan fungsi sebagai tempat rekreasi, perikanan tambak dan pembuangan limbah rumah tangga. Kualitas air Situ Gintung berdasarkan parameter kimia fisik perairan dan total Coliform telah dipengaruhi oleh aktifitas manusia (Wardhana dkk, 2017). Hal ini menunjukkan bahwa perairan Situ Gintung berada diluar baku mutu kelas I (Bahri dkk, 2015).

Kualitas perairan diketahui menggunakan indikator kimia, fisik dan biologi (Kocer \& Sevgili, 2014). Indeks kualitas perairan atau Water Quality Index (WQI) adalah penggabungan pengukuran parameter kimia, fisik dan biologi perairan dengan hasil jumlah satuan yang menggambarkan kualitas air (Lumb et al. 2011). Selain itu, Indeks polusi alga dan saprobit dapat digunakan untuk mengetahui kualitas perairan yang terkontaminasi polusi organik (Palmer, 1969; Dresscher \& van der Mark, 1976). Penelitian kualitas perairan di ekosistem danau telah dilakukan sebelumnya (Pesce \& Wunderlin, 2000; Kannel et al. 2007; Simoes et al. 2008; Lumb et al. 2011; Sharma

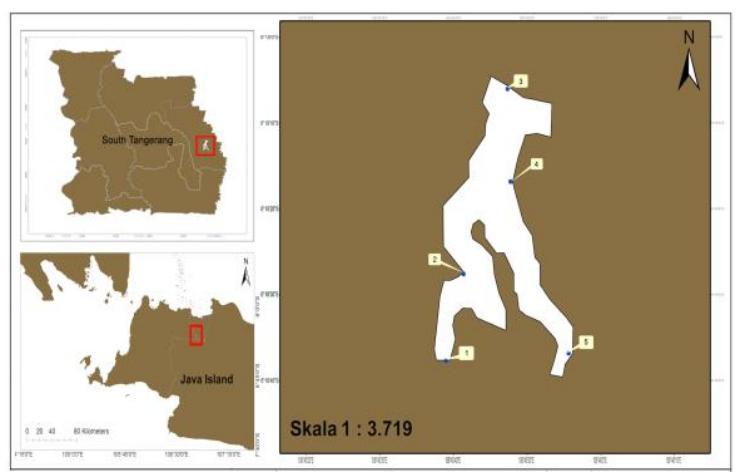

\& Kansal, 2011; Kocer \& Sevgili, 2014; 
Wardhana dkk, 2017) akan tetapi penelitian kualitas perairan menggunakan fitoplankton di periode sebelum, saat dan setelah Ramadan belum dilaporkan. Berdasarkan uraian tersebut, penelitian ini bertujuan mengetahui (i) paramater kimia, fisik dan kualitas perairan menggunakan indeks kualitas perairan (WQI), (ii) klasifikasi fitoplankton menggunakan kodon dan polusi indeks, (iii) indeks Saprobit dan (iv) hubungan parameter kimia dan fisik perairan dengan fitoplankton periode sebelum, saat dan setelah Ramadan.

\section{METODE}

\section{Lokasi dan Waktu}

Penelitian dilakukan danau Situ Gintung di kota Tangerang Selatan, Propinsi Banten, Indonesia (Gambar 1). Sampel diambil pada periode bulan sebelum (MeiJun), saat (Jun-Jul) dan setelah (Jul-Agust) Ramadan 2015 dengan kode masing-masing BR, DR dan AR. Bulan Mei sampai dengan Agustus merupakan musim kemarau dengan rata-rata suhu udara $30-34{ }^{\circ} \mathrm{C} /$ bulan dan persipitasi sebesar $0-87 \mathrm{~mm} /$ bulan (http://www.accuweather.com).

Gambar 1. Lokasi dan stasiun penelitian

Sampel fitoplankton dan parameter kimia, fisik dan biologi perairan dikoleksi secara purposive sampling yaitu berdasarkan rona lingkungan aliran masuk, aliran keluar dan aktifitas sekitar danau yang dilakukan 1 minggu sekali selama 3 minggu dalam setiap periode. Sampling dilakukan di 5 stasiun dengan stasiun 1 dan 5 berada di lokasi inlet, stasiun 3 di outlet, stasiun 2 dekat pemukiman dan stasiun 4 dekat pertanian.

\section{Pengambilan Data}

Fitoplankton dan parameter kimia fisik perairan dikoleksi pada kedalaman 0 meter. Parameter yang diukur adalah suhu, pH, DO, konduktivitas, TDS dengan WQC (Horiba Model U-52) dan kecerahan perairan menggunakan secchi disk. Pengukuran kebutuhan oksigen biologi lima hari $\left(\mathrm{BOD}_{5}\right)$ dengan metode Winkler (Jouanneau et al. 2014) yang dilakukan 1 kali di masing-

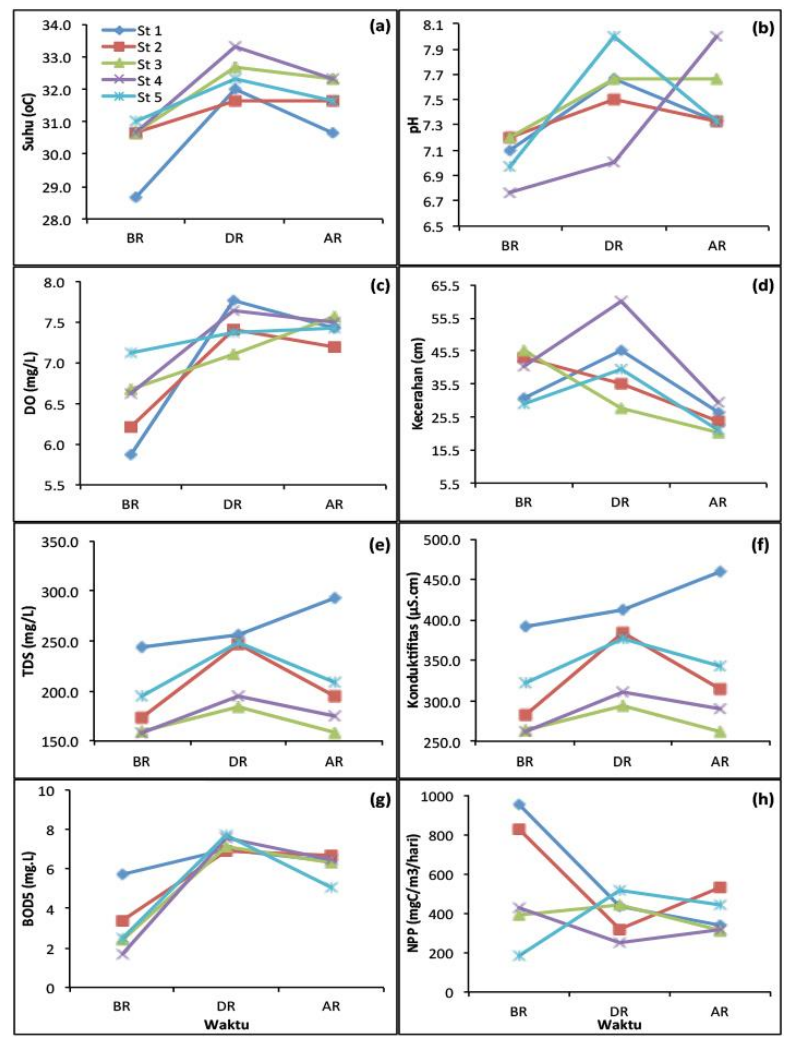

masing stasiun dari 3 minggu setiap bulannya. Produktifitas primer bersih (NPP) perairan diukur dengan metode APHA (2005). Sampel fitoplankton dengan metode filtrasi (Belinger \& Sigee, 2015), yaitu sebanyak 16 liter air dilewatkan pada jaring plankton (Plankton net) berukuran $50 \mu \mathrm{m}$ hingga diperoleh $20 \mathrm{ml}$ dan ditetesi Lugol's iodine 10\% 2-3 tetes. Sampel dibawa dan 
dianalisis di Laboratorium Ekologi, Pusat Laboratorium Terpadu (PLT), UIN Syarif Hidayatullah. Identifikasi fitoplankton dengan merujuk Karacaoglu et al. (2004), van Vuren et al. (2005) dan Belinger \& Sigee (2015).

\section{Analisis Data}

Indeks Kualitas Perairan (WQI) merujuk Kocer \& Sevgili (2014) dengan kriteria dibagi menjadi 5 kelas berdasarkan nilai index yaitu sangat baik (91-100), baik (71-90), sedang (51-70), buruk (26-50) dan sangat buruk (0-25) (Pesce \& Wunderlin, 2000; Kannel et al. 2007). Klasifikasi plankton berdasarkan kodon fitoplankton dengan merujuk Reynolds et al. (2002) dan Padisak et al. (2009).

Analisis one-way ANOVA digunakan untuk mengetahui perbedaan fitoplankton dan parameter perairan periode sebelum, saat dan setelah Ramadan. Korelasi Spearman rank digunakan untuk mengetahui hubungan parameter perairan di Situ Gintung. Perangkat lunak SPSS IBM versi 21 digunakan untuk kedua analisis tersebut. Hubungan antara fitoplankton dengan parameter kimia fisik perairan digunakan Canonical Correspondence Analysis (CCA) (Ter Braak \& Verdonschot, 1995).

\section{HASIL DAN PEMBAHASAN}

\section{Kimia Fisik dan Indeks Kualitas Perairan}

Parameter kimia dan fisik perairan Situ Gintung di semua periode (Gambar 2) memiliki perbedaan yang nyata untuk suhu, kecerahan, TDS dan konduktifitas $(p<0.05)$ kecuali $\mathrm{pH}$, DO dan NPP $(p>0.05)$. Suhu tertinggi terjadi di periode DR dengan nilai $33.3{ }^{\circ} \mathrm{C}$ dan terendah periode $\mathrm{BR} 28.7{ }^{\circ} \mathrm{C}$ (Gambar 2a). Parameter $\mathrm{pH}$ yang tertinggi terjadi pada periode $\mathrm{DR}$ dan $\mathrm{AR}$ dengan nilai 8 dan terendah BR 6.8 (Gambar 2b). Parameter DO memiliki kisaran antara 5.9 $\mathrm{mg} / \mathrm{L}$ sampai dengan $7.8 \mathrm{mg} / \mathrm{L}$, dimana nilai terendah terjadi di BR dan tertinggi di DR (Gambar 2c).

Gambar 2. Nilai rata-rata parameter kimia fisik perairan.

Kecerahan Situ Gintung tertinggi terjadi di periode DR dengan nilai $60.7 \mathrm{~cm}$ dan terendah periode AR $20.8 \mathrm{~cm}$ (Gambar 2d). TDS tertinggi di AR dan terendah di BR dengan nilai masing-masing $293.3 \mathrm{mg} / \mathrm{L}$ dan 158.0 mg/L (Gambar 2e). Konduktifitas yang tertinggi dan terendah terjadi di AR dengan nilai $460.3 \mu \mathrm{S} / \mathrm{cm}$ dan $261.7 \mu \mathrm{S} / \mathrm{cm}$ (Gambar 2f). $\mathrm{BOD}_{5}$ tertinggi terjadi di DR dan terendah di BR dengan nilai $7.7 \mathrm{mg} / \mathrm{L}$ dan $1.7 \mathrm{mg} / \mathrm{L}$ (Gambar 2g). NPP tertinggi dan terendah terjadi di BR dengan nilai 950 dan 183 $\mathrm{mgC} / \mathrm{m} 3 /$ hari (Gambar 2h).

Hasil analisis korelasi parameter kimia fisik di perairan Situ Gintung disajikan pada tabel 1. Spearman's rank menunjukkan bahwa parameter kimia fisik perairan berkorelasi positif yang diantaranya adalah $\mathrm{pH}$ dan DO dengan suhu, DO dengan $\mathrm{pH}$, konduktifitas dengan TDS dan BOD $_{5}$ berkorelasi positif dengan suhu, $\mathrm{pH}$, DO dan TDS, sedangkan produktifitas primer bersih berkorelasi negatif dengan suhu, DO dan $\mathrm{BOD}_{5}$. 
Tabel 1. Korelasi matriks parameter kimia fisik danau Situ Gintung. (*) dan (**) diindikasikan berkorelasi signifikan masing-

\begin{tabular}{lllllllll} 
Variables & ${ }^{\circ} \mathrm{C}$ & $\mathrm{pH}$ & $\mathrm{D} 0$ & Kecerahan & TDS & EC & BOD $_{5}$ & NPP \\
\hline${ }^{\circ} \mathrm{C}$ & 1 & & & & & & & \\
pH & $.566^{*}$ & 1 & & & & & & \\
D0 & $.720^{* *}$ & $.548^{*}$ & 1 & & & & & \\
Kecerahan & -0.059 & -0.295 & -0.07 & 1 & & & & \\
TDS & 0.042 & 0.252 & 0.341 & 0.014 & 1 & & & \\
EC & -0.131 & 0.146 & 0.186 & -0.034 & $.971^{* *}$ & 1 & & \\
B0D & $.757^{* *}$ & $.6011^{*}$ & $.596^{*}$ & 0.071 & $.552^{*}$ & 0.4 & 1 & \\
NPP & -0.365 & 0.027 & $.616^{*}$ & 0.014 & 0.025 & 0.071 & -0.082 & 1 \\
\hline
\end{tabular}

masing 0.05 dan 0.01 .

Keterangan: Satuan DO, TDS dan $\mathrm{BOD}_{5}$ adalah $\mathrm{mg} / \mathrm{L}$, dan Kecerahan $\mathrm{cm}$, EC $\mu \mathrm{S} \cdot \mathrm{cm}^{-1}$ dan Net Produktifitas Primer (NPP) adalah mg $\mathrm{C} / \mathrm{m} 3 / 12$ Jam.

Nilai suhu tertinggi di Situ Gintung mencapai $33{ }^{\circ} \mathrm{C}$ terjadi pada bulan JuniAugust karena diduga dipengaruhi suhu di atmosfir yang mencapai $34{ }^{\circ} \mathrm{C}$. Suhu di Situ Gintung sama dengan penelitian sebelumnya yang berkisar antara 29 sampai $34{ }^{\circ} \mathrm{C}$ (Astuti dkk, 2009; Sugianti dkk, 2015; Wardhana dkk, 2017). Tingginya suhu perairan terjadi akibat musim kemarau mencapai puncaknya pada periode DR. Suhu di perairan danau dipengaruhi oleh cahaya matahari, letak geografis (Lewis, 1987), atmosfir (Wetzel, 2001), musim (Alam et al. 2001; Sarmento et al. 2006), ketinggian dari permukaan laut (Effendi, 2003) dan kedalaman air (Sarmento et al. 2006; Celik \& Ongun, 2007).

Nilai pH Situ Gintung memiliki kisaran yang sama dengan penelitian sebelumnya yaitu 6 sampai 9 (Sulastri, 2011; Nurfadillah et al. 2012; Sulawesty \& Suryono, 2016). Perbedaan $\mathrm{pH}$ di semua periode diduga karena pengaruh musim, menurut Sulastri
(2011) dan Thakur et al. (2013) bahwa pH diperairan dipengaruhi oleh musim. Puncak musim kemarau yang terjadi pada DR mengakibatkan peningkatan $\mathrm{pH}$ pada perairan. Selain itu, perubahan $\mathrm{pH}$ juga disebabkan akibat limbah antropogenik seperti fosfor, kalsium, alkalinitas (Brylinsky \& Mann, 1973), reaksi fotosintesis dan nutrien (Morro et al. 2012). Hasil perubahan pH danau Situ Gintung menunjukkan adanya peningkatan limbah antropogenik pada periode DR dan AR.

DO Situ Gintung memiliki kisaran yang sama dengan penelitian sebelumnya di Situ Lembang pada musim kemarau mencapai 10 $\mathrm{mg} / \mathrm{L}$ (Sulastri, 2011). Nilai DO tertinggi terjadi di periode DR (Gambar 2c) dan memiliki korelasi positif dengan suhu dan $\mathrm{pH}$ perairan (Tabel 1). Hal ini menunjukkan bahwa suhu yang tinggi dapat menyebabkan kadar oksigen menurun dan $\mathrm{pH}$ meningkat. Keberadaan bahan organik perairan dapat berasal dari alam ataupun dari aktifitas rumah tangga dan industri. Menurut Clemente et al. (2005), meningkatnya bahan organik secara langsung mempengaruhi penurunan nilai DO dan $\mathrm{NO}_{3}$ di perairan. Selain itu, kadar oksigen di perairan dipengaruhi oleh suhu, aktifitas bakteri (Blumberg \& Di Toro, 1990), salinitas, tekanan atmosfer (Wetzel, 2001), blooming algae, pH (Xie et al. 2003), turbulensi air (Effendi, 2003) dan musim (Tian et al. 2013).

Nilai kecerahan tertinggi di Situ Gintung terjadi pada periode DR dengan nilai $70 \mathrm{~cm}$ (Gambar 2d) dan berkorelasi negatif 
dengan suhu, DO dan konduktifitas (Tabel 1). Limpasan limbah domestik yang masuk ke badan perairan akan menyebabkan peningkatan bahan organik di perairan. Tingginya nilai bahan organik akan menyebabkan peningkatan jumlah fitoplankton. Penetrasi cahaya yang kurang akibat organisme (fitoplankton), maka nilai kekeruhan akan mengindikasikan ukuran produktivitas suatu perairan. Perbedaan kecerahan di ekosistem danau dipengaruhi oleh kekeruhan, cuaca, padatan tersuspensi (Effendi, 2003), jumlah fitoplankton (Ostojić et al. 2005), zooplankton dan organik terlarut (Torremorell et al. 2007). Lebih lanjut, partikel terlarut dipengaruhi oleh lingkungan danau seperti vegetasi dan nutrien (Scheffer et al. 1993). Berdasarkan kecerahan perairan (Peeters et al. 2009), Situ Gintung memiliki kategori buruk atau sedikit.

Nilai TDS dan EC tertinggi terjadi pada periode DR (Gambar 2e dan 2f), hal ini mengindikasikan bahwa limbah dari aktivitas manusia meningkat. Hasil korelasi Spearman's rank menunjukkan bahwa TDS di Situ Gintung dipengaruhi oleh EC dan $\mathrm{BOD}_{5}$ dan EC dipengaruhi oleh TDS (Tabel 1). Lebih lanjut, musim, suhu (Celik \& Ongun, 2007) dan tingginya gangguan dari aktifitas manusia (Thakur et al. 2013) dapat mempengaruhi TDS di perairan. Koduktifitas (EC) perairan dipengaruhi oleh suhu air, $\mathrm{pH}$, kandungan nutrient, kandungan oksigen, percampuran air, kedalaman air, fotosintesis dan musim (Talling, 2009). Nilai EC di atas $500 \mu \mathrm{S} / \mathrm{cm}$ menunjukkan bahwa perairan memiliki karakteristik semi-lotik (Grabowska et al. 2014).

Nilai BOD $_{5}$ di Situ Gintung tertinggi di periode DR, berdasarakan korelasi Spearman's rank (Tabel 1) dipengaruhi oleh suhu, pH, DO dan TDS yang tinggi (Gambar 2). Hasil penelitian sebelumnya menunjukkan bahwa BOD $_{5}$ perairan sungai dan danau dipengaruhi input nutrient organik (Nandini et al. 2005) dan berasosiasi dengan jumlah klorofil a (Mallin et al. 2006). Polusi bahan organik pada suatu perairan dapat dicirikan dengan tingginya kadar BOD (Rijaluddin dkk, 2017), konsentrasi oksigen yang rendah, tingginya kadar ammonia dan konsentrasi nitrat (Muli \& Mavuti, 2001). Bahan organik yang terdapat pada perairan dapat berasal dari keramba ikan dan limbah domestik rumah tangga (Pitoyo \& Wiryanto, 2002).

Nilai TDS yang tinggi menunjukkan tingginya masukan bahan organik (Rijaluddin dkk, 2017). Adanya dekomposisi bahan organik akan mengakibatkan lepasnya sebagian nutrien pada badan perairan yang menyebabkan peningkatan nilai TDS. Selama proses dekomposisi diperlukan oksigen untuk mengurai bahan organik. Sehingga, semakin besar bahan organik yang didekomposisi maka semakin besar pula nilai $\mathrm{BOD}_{5}$ perairan.

Nilai NPP Situ Gintung lebih rendah dibandingkan dengan NPP Waduk Cengklik (Pitoyo \& Wiryanto, 2002). Perbedaan produktivitas perairan dipengaruhi suhu dan musim (Feresin et al. 2010), aktifitas tambak, kedalaman air (Pitoyo \& Wiryanto, 2002), 
kecerahan dan bahan organik terlarut yang berasal dari daratan (Ask et al. 2009) dan akibat limpasan sungai yang membawa bahan organik dan mineral (Jakubik, 2012). Aliran selokan dari perumahan dan perkebunan dapat menyebabkan meningkatnya nitrat dan bahan organik di perairan (Kopp et al. 2012). Bahan organik yang memasuki perairan waduk dan mengalami proses dekomposisi oleh mikroorganisme perairan menjadi senyawa anorganik yang dapat memacu perkembangan organisme fotoautotrof (fitoplankton) (Pitoyo \& Wiryanto, 2002). Menurut Allan \& Castillo (2007), salah satu biota perairan penghasil produktivitas primer di ekosistem perairan adalah fitoplankton. Sehingga seiring peningkatan jumlah fitoplankton maka akan terjadi peningkatan nilai produktivitas primer suatu perairan.

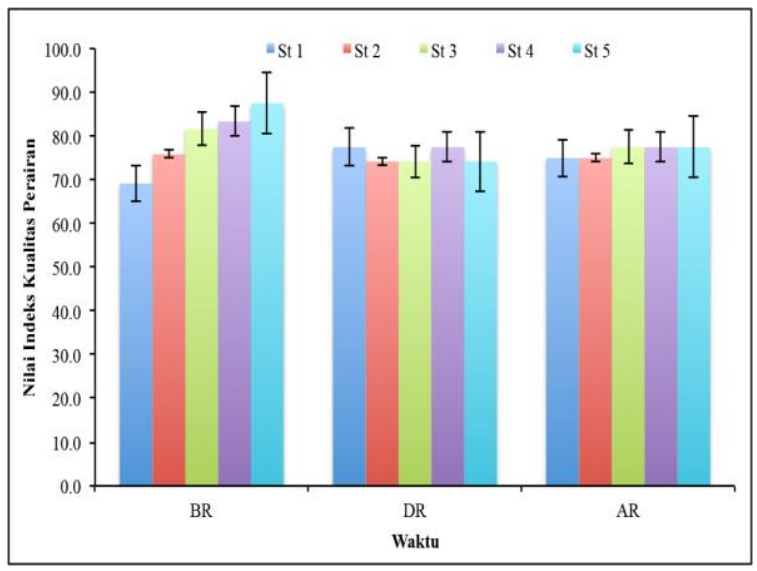

Gambar 3. Indeks kualitas perairan (WQI)

Hasil indeks kualitas perairan atau water quality index (WQI) perairan Situ Gintung di semua periode disajikan pada gambar 3. Kategori WQI di semua periode tidak memiliki perbedaan yang nyata $(p>$
0.05). Rata-rata nilai WQI Situ Gintung berkisar 74 sampai 87 di semua periode kecuali di periode BR dengan nilai 69. Menurut Pesce \& Wunderlin (2000) dan Kannel et al. (2007), nilai index yang masuk kedalam 71 sampai 90 kategori baik dan 51 sampai 70 kategori sedang. Perbedaan nilai WQI perairan di pengaruhi oleh masukkan limbah, perbedaan lokasi antara desa dan kota, dan pengaruh musim (Kannel et al. 2007).

Hasil WQI menunjukkan bahwa perairan Situ Gintung kategori sedang sampai dengan baik. Hasil penelitian sebelumnya pada bulan Agustus 2013 bahwa Situ Gintung tercemar ringan dikarenakan $\mathrm{pH}$ yang rendah dibawah baku mutu air kelas I yaitu 4 sampai dengan 5 dan jumlah total bakteri coliform yang tinggi (Bahri dkk, 2015).

\section{Indeks Polusi Alga dan Saprobit}

Indeks toleransi polusi alga di Situ Gintung memiliki spesies dengan kategori tidak toleran sampai toleran terhadap polusi. Polusi indeks memiliki nilai di masing-masing periode sebesar 69, 60 dan 52 (Tabel 2), hal ini menunjukkan bahwa Situ Gintung tercemar. Menurut Belinger \& Sigee (2015) nilai polusi indeks yang melebihi 20 menunjukkan tercemar tinggi nya polusi organik. Polusi indeks Situ Gintung dilihat dari genus yang toleransi signifikan terhadap polusi seperti Euglena, Oscillatoria, Chlamydomonas, Scenedesmus, Chlorella, Nitzschia dan Navicula (Palmer, 1969). Spesies fitoplankton Situ Gintung ada yang tidak masuk kategori berdasarkan indeks 
polusi (Palmer, 1969) dan kodon fitoplankton (Reynolds et al. 2002; Padisak et al. 2009) sehingga nilai polusinya nol dan tidak terdata (Tabel 2).

Kodon fitoplankton dikategorikan berdasarkan habitat, tipe perwakilan dari spesies, toleransi dan sensitifitas terhadap faktor lingkungan. Hasil dari kategori kodon menunjukkan bahwa Situ Gintung memiliki tingkat kesuburan mesotrofik sampai dengan eutrofik. Hal ini dapat dilihat dari kategori mesotrofik adalah kodon Lo, N, R dan X2 dan eutrofik adalah kodon C, P, Lm, M, V dan D (Reynolds et al. 2002; Padisak et al. 2009). Kandungan nutrient yang masuk di duga berasal dari limbah antropogenik atau penggunaan danau sebagai rekreasi sehingga menyebabkan perubahan tingkat kesuburan. Pertumbuhan dan jumlah algae berkaitan dengan DO dan pH yang meningkat, kandungan nutrien air, penggunaan danau sebagai rekreasi (Ansa et al. 2011) dan beban pencemar yang berlebihan dapat menyebabkan ekosistem danau eutrofik (Xiangcan et al. 2005).

Nilai indeks Saprobit (IS) fitoplankton periode Ramadan di Situ Gintung berkisar antara 0,80 sampai dengan 1,22 (Gambar 4). Hasil dari nilai Saprobit menunjukkan bahwa perairan Situ Gintung di semua periode tercemar ringan. Pada periode BR nilai IS yang terendah adalah 0,80 di stasiun 1 dan 2 , sedangkan yang tertinggi 1,13 di stasiun 3 . Nilai IS yang terendah pada DR terdapat di stasiun 1 sebesar 0,88 dan yang tertinggi 1,11 di stasiun 4. Periode AR nilai IS yang terendah berada di stasiun 1, 3 dan 5 sebesar 1,00 dan yang tertinggi di stasiun 2 sebesar 1,22. Hasil berbeda dari penelitian sebelumnya di danau Skadar kategori betamesosaprobic dengan nilai IS 1 sampai 1,67 (Ramadhan dkk, 2016) yang menunjukkan tercemar sangat ringan dari bahan organik terlarut.

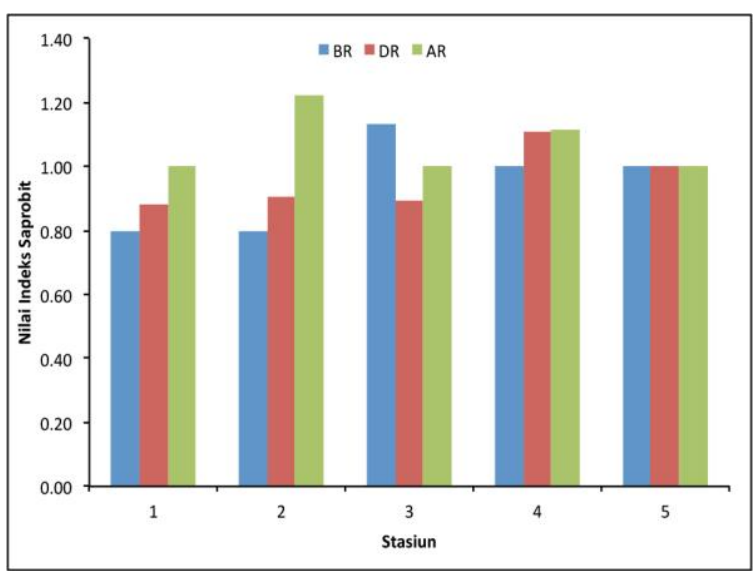

Gambar 4. Indeks Sapbrobit perairan.

Nilai saprobit menunjukkan bahwa bahan pencemar berasal dari organik dan anorganik (Dresscher \& van der Mark, 1976). Polusi organik ditunjukkan dengan rendah nya konsentrasi oksigen, tinggi konsentrasi $\mathrm{BOD}_{5}$, amonia dan nitrat (Muli \& Mavuti, 2001). Nilai saprobitas indeks adalah gambaran tingkat pencemaran di perairan berdasarkan kandungan nutrien dan bahan pencemar. Tingkat bahan pencemar yang melebihi ambang batas yang diakibatkan oleh aktifitas manusia (Duan et al. 2009), toleransi cahaya rendah, ratio N/P yang rendah, $\mathrm{pH}$ dan suhu yang optimum (Belinger \& Sigee, 2015) dapat menyebabkan blooming algae di ekosistem danau.

\section{Kimia Fisik Perairan dengan Fitoplankton}


Hasil korelasi parameter kimia fisik perairan dengan fitoplankton menggunakan Canonical Correspondence Analysis (CCA) ditunjukkan pada gambar 5. Hasil menunjukkan komunitas fitoplankton dipengaruhi oleh kimia fisik. Fitoplankton Chlorophyta, Cyanophyta dan Bacillariophyta berkorelasi dengan kecerahan, suhu, DO dan $\mathrm{BOD}_{5}$, sedangkan Chrysophyta, Euglenophyta, Cryptophyta dan Dinophyta berkorelasi dengan $\mathrm{pH}$, TDS dan EC. Kimia fisik perairan yang paling berpengaruh signifikan terhadap fitoplankton adalah $\mathrm{BOD}_{5}$ dengan nilai $\mathrm{P}$ 0.002 (Tabel 3).

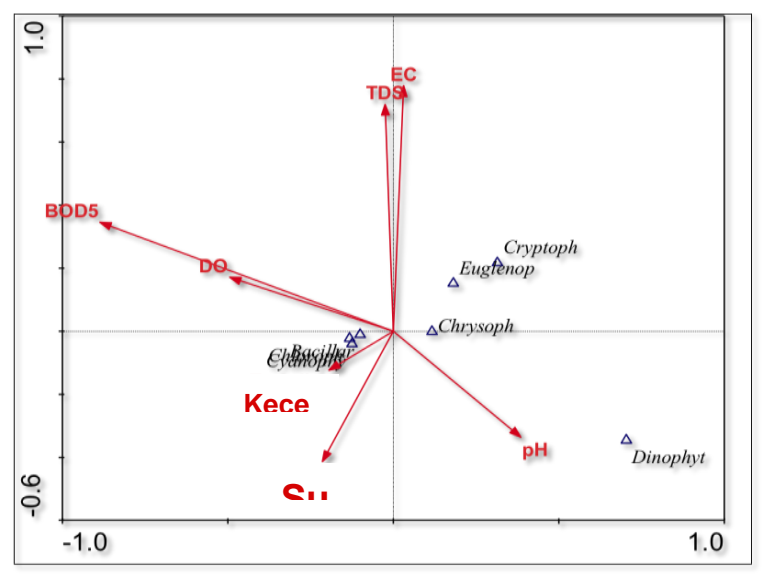

Gambar 5. Canonical correspondence analysis parameter kimia fisik perairan dengan fitoplankton danau Situ Gintung.

Situ Gintung periode Ramadan memiliki suhu yang tinggi dan berkorelasi dengan $\mathrm{BOD}_{5}$ (Tabel 3). Menurut Thakur et al. (2013) tingginya nilai BOD $_{5}$ mengindikasikan kehadiran tingginya jumlah organik yang berasal dari tempat tinggal manusia. Hasil penelitian sebelumnya menunjukkan bahwa tingginya $\mathrm{BOD}_{5}$ di musim panas dipengaruhi nutrient fosfor (Heiskary \& Markus, 2001) dan masukkan nutrient dipengaruhi musim dengan tertinggi di musim panas dan nutrient kemudian mempengaruhi jumlah klorofil a (Li et al. 2011). Nilai klorofil a perairan tersebut erat kaitannya dengan biomassa fitoplankton. Seiring peningkatan biomassa fitoplankton akan menyebabkan kenaikan nilai DO. Menurut Effendi (2003), oksigen di perairan danau lebih banyak dihasilkan oleh fotosintesis fitoplankton.

Table 3. Hasil CCA dengan metode seleksi langkah maju (forward selection) dan uji menggunakan Monte Carlo Permutation dengan 499 permutasi acak.

\begin{tabular}{llll}
\hline Parameter & $\mathrm{F}$ & $\lambda$ & $\mathrm{P}$ \\
\hline BOD $_{5}$ & 6,930 & 1,352 & $0.002^{*}$ \\
EC & 1,610 & 110,712 & 0,196 \\
DO & 1,410 & 4,609 & 0,228 \\
pH & 0,680 & 1,717 & 0,608 \\
Suhu & 0,840 & 2,494 & 0,446 \\
TDS & 0,400 & 124,055 & 0,772 \\
Kecerahan & 0,090 & 1,115 & 0,984 \\
\hline
\end{tabular}

Ket : $\lambda$ : eigenvalue, $(*)$ : berbeda nyata $(\mathrm{p}<$ $0,05)$.

Hasil penelitian menunjukkan bahwa Chlorophyta dan Cyanophyta di Situ Gintung melimpah di semua periode. Chlorophyta adalah fitoplankton yang memiliki kisaran yang luas terhadap parameter kimia fisik, sehingga menjadi dominan atau blooming dengan kondisi danau eutrofik (Belinger \& Sigee, 2015). Spesies Chlorophyta ditemukan melimpah dengan kondisi suhu, DO dan BOD $_{5}$ yang tinggi (Thakur et al. 2013). Selain itu, Chlorophyta berkorelasi dengan turbiditas musim kemarau (Lung'ayia et al. 2000), suhu, DO, salinitas, TDS, konduktifitas, pH (Çelekli et al. 2014) dan total fosfat (Mohebbi et al. 2016). Cyanobacteria atau Cyanophyta di danau Manyas melimpah di musim panas dan 
hasil CCA menunjukkan berkorelasi dengan kecerahan, kedalaman (Nabout et al. 2006), suhu yang tinggi, turbiditas, TDS dan debit air yang rendah (Celik \& Ongun, 2007). Bacillariophyta di ekosistem danau berkorelasi dengan kecerahan (Da Costa \& Dantas, 2011) dan di ekosistem sungai dengan DO (El-sheekh et al. 2010). Chrysophyta di Situ Gintung hanya ditemukan Synura sp. di periode BR dan AR, hal ini diduga karena pH perairan. Spesies Synura sp. digunakan sebagai bioindikator perairan asam, berkorelasi dengan $\mathrm{pH}$ dan salinitas (Belinger \& Sigee, 2015). Selain itu, spesies ini berkorelasi dengan silikat, kedalaman, NO3-N, posfor terlarut dan ketinggian (Tolotti et al. 2003). Euglenophyta ditemukan di semua periode dan berkorelasi dengan kimia fisik perairan. Menurut Çelekli et al. (2014) bahwa Euglenophyta berkorelasi dengan TDS dan EC. Spesies dari Euglenophyta ditemukan di lingkungan yang melimpah bahan pembusukan organik, dapat bertahan dengan kondisi $\mathrm{pH}$ ekstrim dan kisaran salinitas yang luas (Belinger \& Sigee, 2015).

Dua dari tiga spesies Cryptophyta ditemukan di semua periode dengan nilai kimia fisik perairan yang tinggi (Tabel 2 dan Gambar 2). Menurut Thakur et al. (2013) Cryptophyta ditemukan dengan $\mathrm{pH}$, TDS dan EC yang tinggi. Lebih lanjut, spesies dari Cryptophyta dan Dinophyta memiliki korelasi dengan kimia fisik perairan yaitu kedalaman, posfor terlarut, ketinggian, suhu (Tolotti et al. 2003), TDS dan EC (Çelekli et al. 2014).
Cryptophyta dapat hidup oligotrofik sampai dengan eutrofik, tipe yang hidup di wilayah beriklim sedang dan dapat tumbuh pada kondisi cahaya yang terbatas (Belinger \& Sigee, 2015). Fitoplankton Dinophyta ditemukan 1 spesies yaitu Peridinium sp. di periode $\mathrm{BR}$ dan AR (Tabel 2), hal ini diduga dipengaruhi dan berkorelasi (Gambar 5) dengan $\mathrm{pH}$ yang tinggi. Hasil penelitian sebelumnya menunjukkan bahwa Dinophyta ditemukan 2 spesies dengan kondisi pH, TDS dan EC yang tinggi (Thakur et al. 2013).

\section{KESIMPULAN}

Parameter kimia fisik Situ Gintung di semua periode tidak memiliki perbedaan nyata, kecuali pH, DO dan NPP dengan indeks kualitas perairan (WQI) tergolong sedang sampai dengan baik di semua periode. Klasifikasi fitoplankton menunjukkan kategori meso sampai eutrofik dan nilai indeks polusi alga dan Saprobit menunjukkan tercemar di semua periode. Hasil dari CCA menunjukkan bahwa fitoplankton secara keseluruhan dipengaruhi oleh nilai BOD $_{5}$ perairan.

Jenis-jenis polusi organik dan logam yang masuk ke perairan danau diperlukan untuk penelitian lebih lanjut. Hal ini untuk mendukung dan mengetahui adanya perubahan perilaku dan aktifitas masyarakat di periode sebelum, saat dan setelah Ramadan. 


\section{DAFTAR PUSTAKA}

Afifi, ZEM. 1997. Daily practices, study performance and health during the ramadan fast. The Journal of the Royal Society for the Promotion of Health. 117: 231-235.

Alam, MGM, Jahan, N., Thalib, L., Wei, B. \& Maekawa, T. 2001. Effects of environmental factors on the seasonally change of phytoplankton populations in a closed freshwater pond. Environment International. 27: 363-371.

Allan, JD., \& Castillo, MM. 2007. Stream ecology : Structure and function of running waters, $2^{\text {nd }}$ Edition, Springer, Berlin.

Ansa, EDO., Lubberding, HJ., Ampofo, JA., \& Gijzen, HJ. 2011. The role of algae in the removal of escherichia coli in a tropical eutrophic lake. Ecological Engineering. 37:317-324.

Astuti, LP, Warsa, A., \& Satria, H. 2009. Kualitas air dan kelimpahan plankton di danau sentani, kabupaten jayapura. Jurnal Perikanan. 11:66-77.

American Public Health Association (APHA). 2005. Standard method for examination of water and wastewater, $21^{\text {st }}$ Ed. APHA, AWWA, WEF, USA.

Bahri, S., Ramadhan, F., \& Reihannisa, I. 2015. Kualitas perairan Situ Gintung Tangerang Selatan. Biogenesis. 3:16-22.

Bellinger, EG., \& Sigee, DC. 2015. Freshwater algae: Identification and use as bioindicators. $2^{\text {nd }}$ Edition. John Wiley and Sons, Ltd, UK.

Blumberg, AF., \& Di Toro, DM. 1990. Effects of climate warming on dissolved oxygen concentrations in lake Erie. Transactions of the American Fisheries Society. 119:210-223.

Brönmark, C., \& Hansson, LA. 2002. Environmental issues in lakes and ponds: current state and perspectives. Environmental Conservation. 29:290306.

Brylinsky, M., \& Mann, KH. 1973. An analysis of factors governing productivity in lakes and reservoirs. Limnology and Oceanography. 18:1-14.

Cai, Y., Gong, Z., \& Qin, B. 2011. Influences of habitat type and environmental variables on benthic macroinvertebrate communities in a large shallow subtropical lake (lake Taihu, China). Annales de Limnologie - International Journal of Limnology. 47:85-95.

Çelekli, A., Öztürk, B., \& Kapi, M. 2014. Relationship between phytoplankton composition and environmental variables in an artificial pond. Algal Research. 5:37-41.

Celik, K., \& Ongun, T. 2007. The relationships between certain physical and chemical variables and the seasonal dynamics of phytoplankton assemblages of two inlets of a shallow hypertrophic lake with different nutrient inputs. Environmental Monitoring and Assessment. 124:321-330.

Chen, Y., Zhao, K., Wu, Y., Gao, S., Cao, W., Bo, Y., Shang, Z., Wu, J. \& Zhou, F. 2016. Spatio-temporal patterns and source identification of water pollution in lake Taihu (China). Water. 8(3):1-11.

Clemente, JM, Mazzeo, N., Gorga, J., \& Meerhoff, M. 2005. Succession and collapse of macrozoobenthos in a subtropical hypertrophic lake under restoration (lake Rodo, Uruguay). Aquatic Ecology. 39:455-464.

Da Costa, DF., \& Dantas, Ê.W. 2011. Diversity of phytoplankton community in different urban aquatic ecosystems in metropolitan João Pessoa, state of Paraíba, Brazil. Acta Limnologica Brasiliensia. 23:394-405.

Deng, J., Qin, B., Paerl, HW, Zhang, Y., Wu, P., Ma, J. \& Chen, Y. 2014. Effects of 
nutrients, temperature and their interactions on spring phytoplankton community succession in lake Taihu, China. Plos ONE 9(12):1-19.

Dresscher, TGN., \& van der Mark, H., 1976. A simplified method for the biological assesment of the quality of fresh and slightly brackish water. Hydrobiologia. 48:199-201.

Duan, H., Ma, R., Xu, X., Kong, F., Zhang, S., Kong, W., Hao, J. \& Shang, L., 2009, Two-decade reconstruction of algal blooms in china's lake taihu, Environmental Science and Technology $43,3522-3528$.

Effendi, H. 2003. Telaah kualitas air bagi pengelolaan sumber daya dan lingkungan perairan. Kanisius. Yogyakarta, $249 \mathrm{pp}$.

El-Sheekh, MM., Deyab, MAI., Desouki, SS., \& Eladl, M. 2010. Phytoplankton compositions as a response of water quality in el salam canal hadous drain and damietta branch of river nile Egypt. Pakistan Journal of Botany. 42:26212633.

Feresin, EG., Arcifa, MS., da Silva, LHS., \& Esguícero, ALH. 2010. Primary productivity of the phytoplankton in a tropical brazilian shallow lake: experiments in the lake and in mesocosms. Acta Limnologica Brasiliensia. 22:384-396.

Grabowska, M., Glińska-Lewczuk, K., Obolewski, K., Burandt, P., Kobus, S., Dunalska, J., Kujawa, R., Goździejewska, A., \& Skrzypczak, A. 2014 Effects of hydrological and physicochemical factors on phytoplankton communities in floodplain lakes. Polish Journal of Environmental Studies. 23:713-725.

Heiskary, S., \& Markus, H. 2001. Establishing relationships among nutrient concentrations, phytoplankton abundance, and biochemical oxygen demand in minnesota, usa, rivers. Lake and Reservoir Management. 17:251262.
Jakubik, B. 2012. Life strategies of viviparidae (gastropoda: caenogastropoda: architaenioglossa) in various aquatic habitats: viviparus viviparus (Linnaeus, 1758) and v. contectus (Millet, 1813). Folia malacologica. 20:145-179.

Jouanneau, S., Recoules, L., Durand, MJ., Boukabache, A., Picot, V., Primault, Y., Lakel, A., Sengelin, M., Barillon, B. \& Thouand, G. 2014. Methods for assessing biochemical oxygen demand (BOD): A review. Water Research. 49:62-82.

Kannel, PR., Lee, S., Lee, YS., Kanel, SR., \& Khan, S.P. 2007. Application of water quality indices and dissolved oxygen as indicators for river water classification and urban impact assessment. Environmental Monitoring and Assessment. 132:93-110.

Karacaoglu, D., Dere, S. \& Dalkiran, N. 2004. A taxonomy study on phytoplankton of lake Uluabat (Bursa). Turkish Journal of Botany. 28:473-485.

Kocer, MAT., \& Sevgili, H. 2014. Parameters selection for water quality index in the assessment of the environmental impacts of land-based trout farms. Ecological Indicators. 36:672-681.

Kopp, R., Vítek, T., Štastný, J., Sukop, I., Brabec, T., Ziková, A., Spurný, P., \& Mareš, J. 2012. Water quality and biotic community of a highland stream under the influence of a eutrophic fishpond. International Review Hydrobiology. 97:26-40.

Li, YP., Acharya, K., Stone, MC., Yu, ZB., Young, MH., Shafer, DS., Zhu, J., Gray, K., Stone, A., Fan, L., Tang, C., \& Warwick, J. 2011. Spatio-temporal patterns in nutrient loads, nutrient concentrations, and algal biomass in lake Taihu, China. Lake and Reservoir Management. 27:298309. 
Lewis, WM. 1987. Tropical Limnology. Annual Review of Ecology and Systematics. 18:159-184.

Lukman \& Hidayat. 2002. Pembebanan dan distribusi bahan organik di waduk Cirata. Jurnal Teknologi Lingkungan 3:129-135.

Lumb, A., Sharma, TC., \& Bibeault, JF. 2011. A review of genesis and evolution of water quality index (WQI) and some future directions. Water Quality, Exposure and Health. 3:11-24.

Lung'ayia, HBO., M'harzi, A., Tackx, M., Gichuki, J., \& Symoens, JJ. 2000. Phytoplankton community structure and environment in the kenyan waters of lake Victoria. Freshwater Biology. 43:529-543.

Mallin, MA., Johnson, VL., Ensign, SH., \& MacPherson, TA. 2006. Factors contributing to hypoxia in rivers, lakes, and streams. Limnology and Oceanography. 51:690-701.

Mohebbi, F., Riahi, H., Sheidaei, M., \& Shariatmadari, Z. 2016. Phytoplankton of aras dam reservoir (Iran): An attempt to assess water quality. Iranian Journal of Fisheries Sciences. 15:13181336.

Morro, CA., Moyà, NG., \& Martínez-Taberner, A. 2012. Phytoplankton as bioindicator for waste stabilization ponds. Journal of Environmental

Management. 95(SUPPL.).

Muhtarom, K. 2010. Perilaku konsumsi masyarakat Jakarta Timur sebelum dan saat Ramadhan. Al-Iqtishad. 2:55-78.

Muli, J.R., \& Mavuti, KM. 2001. The benthic macrofauna community of Kenyan waters of lake Victoria. Hydrobiologia. 458:83-90.

Nabout, JC., Nogueira, IS., \& Oliveira, LG. 2006. Phytoplankton community of floodplain lakes of the araguaia river, brazil, in the rainy and dry seasons.
Journal of Plankton Research. 28:181193.

Nandini, S., Ramírez-García, P., \& Sarma, PPP. 2005. Seasonal variations in the species diversity of planktonic rotifers in lake Xochimilco, Mexico. Journal of Freshwater Ecology. 20:287-294.

Nurfadillah, Damar, A., \& Adiwilaga, EM. 2012. Komunitas fitoplankton di perairan danau laut tawar kabupaten aceh tengah, Provinsi Aceh. Depik. 1:9398.

Ostojić, A., Ćurčić, S., Čomić, L., \& Marina, T. 2005. Estimate of the eutrophication process in the gruža reservoir (Serbia and Montenegro). Acta Hydrochimica et Hydrobiologica. 33:605-613.

Padisak, J., Crossetti, LO., \& Naselli-Flores, L. 2009. Use and misuse in the application of the phytoplankton functional classification: a critical review with updates. Hydrobiologia. 621:1-19.

Palmer, CM. 1969. A composite rating of algae tolerating organic pollution. Journal of Phycology. 5:78-82.

Peeters, ETHM., Franken, RJM., Jeppesen, E., Moss, B., Becares, E., Hansson, LA., Romo, S., Kairesalo, T., Gross, EM., van Donk, E., Noges, T., Irvine, K., Kornijow, R., \& Scheffer, M. 2009. Assessing ecological quality of shallow lakes: Does knowledge of transparency suffice?. Basic and Applied Ecology. 10:89-96.

Pesce, SF., \& Wunderlin, DA. 2000. Use of water quality indices to verify the impact of Cordoba city (Argentina) on Suquia river. Water Research. 34:29152926.

Pitoyo, A., \& Wiryanto. 2002. Produktifitas primer perairan waduk Cengklik Boyolali. Biodiversitas. 3:189-195.

Ra, HR. 2016. The Ramadan effects on the economy: Focused on the volatility of economic variables of Indonesia and 
Malaysia. Korea and the World Economy. 17:61-98.

Ramadhan, F., Rijaluddin, AF., \& Assuyuti, YM. 2016. Studi indeks saprobik dan komposisi fitoplankton pada musim hujan di Situ Gunung, Sukabumi, Jawa Barat. Al-kauniyah Jurnal Biologi. 9:95102.

Reynolds, CS., Huszar, V., Kruk, C., NaselliFlores, L., \& Melo, S. 2002. Towards a functional classification of the freshwater phytoplankton. Journal of Plankton Research. 24:417-428.

Rijaluddin, AF., Wijayanti, F. \& Haryadi, J. 2017. Struktur komunitas makrozoobentos di Situ Gintung, Situ Bungur dan Situ Kuru, Ciputat Timur. Jurnal Teknologi Lingkungan. 18:139147.

Sarmento, H., Isumbisho, M. \& Descy, JP. 2006. Phytoplankton ecology of lake Kivu (Eastern Africa). Journal of Plankton Research. 28:815-829.

Scheffer, M., Hosper, SH., Meijer, ML., Moss, B., \& Jeppesen, E. 1993. Alternative equilibria in shallow lakes. Trends in Ecology and Evolution. 8:275-279.

Sharma, D., \& Kansal, A., 2011. Water quality analysis of river Yamuna using water quality index in the national capital territory, India (2000-2009). Applied Water Science. 1:147-157.

Simoes, FDS., Moreira, AB., Bisinoti, MC., Gimenez, SMN., \& Yabe, MJS. 2008. Water quality index as a simple indicator of aquaculture effects on aquatic bodies. Ecological Indicators 8:476-484.

Sugianti, Y., Putri, MRA., \& Krismono, 2015. Karakteristik komunitas dan kelimpahan fitoplankton di danau Talaga, Sulawesi Tengah. Limnotek 22:86-95.

Sulastri. 2011. Perubahan temporal komposisi dan kelimpahan fitoplankton di situ Lembang, Jawa Barat. Limnotek. 18:1-14.

Sulawesty, F., \& Suryono, T. 2016. Komunitas fitoplankton kaitannya dengan kualitas perairan danau Sentani. Limnotek Perairan Darat Tropis di Indonesia 23:61-74.

Talling, JF. 2009. Electrical conductance: A versatile guide in freshwater science. Freshwater Reviews. 2:65-78.

Ter Braak, CJF., \& Verdonschot, PFM. 1995. Canonical correspondence analysis and related multivariate methods in aquatic ecology. Aquatic Sciences. 57:255-289.

Thakur, RK., Jindal, R., Singh, UB., \& Ahluwalia, AS. 2013. Plankton diversity and water quality assessment of three freshwater lakes of Mandi (Himachal Pradesh, India) with special reference to planktonic indicators. Environmental Monitoring and Assessment. 185:83558373.

Tian, C., Pei, H., Hu, W. \& Xie, J. 2013. Phytoplankton variation and its relationship with the environmental factors in Nansi lake, China. Environmental Monitoring and Assessment. 185:295-310.

Tolotti, M., Thies, H., Cantonati, M., Hansen, CME., \& Thaler B. 2003. Flagellate algae (chrysophyceae, dinophyceae, cryptophyceae) in 48 high mountain lakes of the northern and nouthern slope of the eastern Alps: biodiversity, taxa distribution and their driving variables. Hydrobiologia. 502:331-348.

Torremorell, A., Bustigorry, J., Escaray, R., Zagarese, HE. 2007. Seasonal dynamics of a large, shallow lake, laguna chascomus: The role of light limitation and other physical variables. Limnologica. 37:100-108.

van Vuren, SJ., Taylor, J., van Ginkel, C. \& Gerber, A. 2005. Easy Identification of the most common freshwater algae: $A$ guide for the identification of 
microscopic algae in south african freshwaters. North-West University and Department of Water Affairs and Forestry.

Wardhana, HI., Nadila, A., Mardiansyah, Ramadhan, F., \& Rijaluddin, AF. 2017. Kualitas perairan pada bulan ramadan di Situ Gintung, Tangerang Selatan. Banten. Jurnal Biodjati. 2:9-20.

Wardiha, MW., Putri, PSA., Setyawati, LM., \& Muhajirin. 2014. Timbulan dan komposisi sampah di kawasan perkantoran dan wisma (Studi kasus: Werdhapura village center, kota Denpasar, provinsi Bali). Jurnal Bumi Lestari. 14:27-38.

Wetzel, RG. 2001. Limnology: Lake and river ecosystems, $3^{\text {rd }}$ ed. Academic Press, San Diego, CA.

Wilhelm, SW., Farnsley, SE., LeCleir, GR., Layton, AC., Satchwell, MF., DeBruyn, JM., Boyer, GL., Zhu, G., \& Paerl, HW. 2011. The relationships between nutrients, cyanobacterial toxins and the microbial community in Taihu (lake Tai), China. Harmful Algae. 10:207-215.

Xiangcan, J., Qiujin, X., \& Changzhu, H. 2005. Current status and future tendency of lake eutrophication in China. Science in China Series C Life Sciences. 48:948-954.

Xie, LQ., Xie, P., \& Tang, HJ., 2003. Enhancement of dissolved phosphorus release from sediment to lake water by microcystis blooms - An enclosure experiment in a hyper-eutrophic, subtropical Chinese lake. Environmental Pollution. 122:391-399.

Yildirim, H., Capone, R., Karanlik, A., Bottalico, F., Debs, P., \& El Bilali, H. 2016. Food wastage in turkey: An exploratory survey on household food waste. Journal of Food and Nutrition Research. 4:483-489.

Zhang, D., Xie, P., Liu, Y. \& Qiu, T. 2009. Transfer, distribution and bioaccumulation of microcystins in the aquatic food web in lake Taihu, China, with potential risks to human health. Science of The Total Environment. 407:2191-2199. 
Tabel 2. Polusi indeks dan kodon fitoplankton Situ Gintung periode Ramadan.

\begin{tabular}{|c|c|c|c|c|c|c|c|c|}
\hline \multirow{2}{*}{ Divisi } & \multirow{2}{*}{ Spesies } & \multicolumn{2}{|c|}{ BR } & \multicolumn{2}{|c|}{ DR } & \multicolumn{2}{|c|}{ AR } & \multirow{2}{*}{ Kodon } \\
\hline & & KH & IP & KH & IP & KH & IP & \\
\hline \multirow{15}{*}{ Bacillariophyta } & Actinocyclus sp. & + & 0 & + & 0 & + & 0 & $\mathrm{D}$ \\
\hline & Actinoptychus sp. & + & 0 & - & 0 & - & 0 & NR \\
\hline & Asterionella sp. & + & 0 & - & 0 & - & 0 & $\mathrm{C}$ \\
\hline & Aulacodiscus sp. & + & 0 & - & 0 & - & 0 & NR \\
\hline & Caloneis sp. & - & 0 & + & 0 & - & 0 & NR \\
\hline & Coconeis pedicula Ehrenb & + & 0 & + & 0 & + & 0 & NR \\
\hline & Diatoma sp. & + & 0 & + & 0 & + & 0 & NR \\
\hline & Diploneis sp. & + & 0 & + & 0 & + & 0 & NR \\
\hline & Fragilaria sp. & - & 0 & + & 0 & - & 0 & $\mathrm{P}$ \\
\hline & Navicula sp. & + & 3 & - & 0 & - & 0 & MP \\
\hline & N. pelagi A.W.F. Schmidt & - & 0 & + & 3 & - & 0 & NR \\
\hline & N. rhynchocephala Kütz & + & 3 & - & 0 & - & 0 & NR \\
\hline & Nitzschia acicularis (Kütz) W.Sm. & + & 3 & + & 3 & + & 3 & $\mathrm{D}$ \\
\hline & Rhopaldia sp. & - & 0 & - & 0 & + & 0 & NR \\
\hline & Synedra sp. & - & 0 & - & 0 & + & 2 & $\mathrm{D}$ \\
\hline \multirow{22}{*}{ Chlorophyta } & Actinastrum sp. & + & 0 & + & 0 & + & 0 & $\mathrm{G}$ \\
\hline & Ankistrodesmus sp. & + & 2 & + & 2 & - & 0 & $\mathrm{X} 1$ \\
\hline & Ankyra sp. & - & 0 & + & 0 & - & 0 & $\mathrm{X} 1$ \\
\hline & Chlamydomonas sp. & + & 4 & + & 4 & + & 4 & $\mathrm{X} 2$ \\
\hline & Chlorella sp. & + & 3 & + & 3 & + & 3 & $\mathrm{X} 1$ \\
\hline & Closterium sp. & - & 0 & + & 1 & + & 1 & $\mathrm{P}$ \\
\hline & Coelastrum sp. & - & 0 & + & 0 & + & 0 & $\mathrm{~J}$ \\
\hline & Cosmarium sp. & + & 0 & + & 0 & + & 0 & $\mathrm{~N}$ \\
\hline & Crucigenia ferestuata Schmidle & - & 0 & + & 0 & - & 0 & $\mathrm{~J}$ \\
\hline & Dictyosphaerium sp. & - & 0 & + & 0 & + & 0 & $\mathrm{~F}$ \\
\hline & Eudorina elegans Ehrenberg & + & 0 & + & 0 & + & 0 & G \\
\hline & Gonium sp. & + & 0 & - & 0 & + & 0 & W1 \\
\hline & Haematococcus sp. & - & 0 & - & 0 & + & 0 & NR \\
\hline & Monoraphidium sp. & + & 0 & + & 0 & + & 0 & $\mathrm{X} 1$ \\
\hline & Oedogonium sp. & - & 0 & + & 0 & - & 0 & NR \\
\hline & Pandorina morum (O.F.Müll.) Bory & + & 1 & + & 1 & + & 1 & $\mathrm{G}$ \\
\hline & Pleurococcus sp. & + & 0 & - & 0 & - & 0 & NR \\
\hline & $\begin{array}{l}\text { Scenedesmus acuminatus } \\
\text { (Lagerheim) Chodat }\end{array}$ & + & 4 & - & 0 & - & 0 & NR \\
\hline & S. bicaudatus Debus & + & 4 & + & 4 & + & 4 & NR \\
\hline & S. obliquus (Turpin) Kütz & - & 0 & + & 4 & + & 4 & NR \\
\hline & S. obtusus Meyen & + & 4 & + & 4 & + & 4 & NR \\
\hline & S. ornatus (Lemmerm.) G.M.Sm. & + & 4 & + & 4 & + & 4 & NR \\
\hline
\end{tabular}




\begin{tabular}{|c|c|c|c|c|c|c|c|c|}
\hline & Selenastrum sp. & + & 0 & + & 0 & + & 0 & NR \\
\hline & Sphaerocystis sp. & + & 0 & + & 0 & + & 0 & $\mathrm{~F}$ \\
\hline & Spirogyra sp. & - & 0 & + & 0 & - & 0 & NR \\
\hline & Staurastrum sp. & - & 0 & + & 0 & - & 0 & $\mathrm{P}$ \\
\hline & Tetraedron sp. & + & 0 & + & 0 & + & 0 & $\mathrm{~J}$ \\
\hline & Tetrastrum sp. & + & 0 & + & 0 & + & 0 & $\mathrm{~J}$ \\
\hline Chrysophyta & Synura sp. & + & 0 & - & 0 & + & 0 & W1 \\
\hline \multirow{3}{*}{ Cryptophyta } & Cryptomonas sp. & + & 0 & + & 0 & + & 0 & $\mathrm{Y}$ \\
\hline & Haematococcus sp. & + & 0 & + & 0 & + & 0 & NR \\
\hline & Rhodomonas sp. & + & 0 & - & 0 & - & 0 & NR \\
\hline \multirow{11}{*}{ Cyanophyta } & Anabaena sp. & + & 0 & + & 0 & + & 0 & $\mathrm{H} 1$ \\
\hline & Chroococcus sp. & + & 0 & + & 0 & + & 0 & Lo \\
\hline & Cylindrospermopsis sp. & + & 0 & + & 0 & + & 0 & SN \\
\hline & Gloeocapsa sp. & + & 0 & + & 0 & + & 0 & NR \\
\hline & Merismopedia punctata Meyen & + & 0 & + & 0 & + & 0 & Lo \\
\hline & M. trolleri H. Bachm & - & 0 & - & 0 & + & 0 & NR \\
\hline & Microcystis aeruginosa (Kütz) Kütz. & + & 0 & - & 0 & + & 0 & $\mathrm{Lm} / \mathrm{M}$ \\
\hline & Oscillatoria agardhii & + & 5 & - & 0 & - & 0 & $\mathrm{R}$ \\
\hline & O. brevis Kütz. Ex Gomont & + & 5 & + & 5 & + & 5 & $\mathrm{R}$ \\
\hline & O. princeps Vaucher ex Gomont & + & 5 & + & 5 & + & 5 & $\mathrm{R}$ \\
\hline & $\begin{array}{l}\text { O. rubescens De Candolle ex } \\
\text { Gomont }\end{array}$ & + & 5 & + & 5 & + & 5 & $\mathrm{R}$ \\
\hline Dinophyta & Peridinium sp. & + & 0 & - & 0 & + & 0 & Lo \\
\hline \multirow{5}{*}{ Euglenophyta } & Euglenoids sp. & - & 0 & + & 5 & + & 5 & W1 \\
\hline & Euglena sp. & + & 5 & - & 0 & - & 0 & W1 \\
\hline & E. proxima P.A. Dang & + & 5 & + & 5 & - & 0 & W1 \\
\hline & Phacus sp. & + & 2 & + & 2 & + & 2 & W1 \\
\hline & P. triqueter (Ehrenb) Perty & + & 2 & - & 0 & - & 0 & W1 \\
\hline
\end{tabular}

Keterangan: KH adalah kehadiran, IP adalah Indeks Polusi, (+) ada, (-) tidak ada, polusi berdasarkan genus (Palmer, 1969), kodon fitoplankton merujuk Reynolds et al. (2002) dan Padisak et al. (2009). 0 dan NR tidak tercatat di literatur. 